University of Nebraska - Lincoln

DigitalCommons@University of Nebraska - Lincoln

$5-17-2019$

\title{
Inhibition of Aflatoxin Formation in Aspergillus Species by Peanut (Arachis hypogaea) Seed Stilbenoids in the Course of Peanut- Fungus Interaction
}

\author{
Victor S. Sobolev \\ United States Department of Agriculture, Victor.Sobolev@usda.gov \\ Travis Walk \\ United States Department of Agriculture \\ Renee Arias \\ United States Department of Agriculture, renee.arias@usda.gov \\ Alicia Massa \\ United States Department of Agriculture, alicia.massa@usda.gov \\ Marshall Lamb \\ United States Department of Agriculture, marshall.lamb@usda.gov
}

Follow this and additional works at: https://digitalcommons.unl.edu/usdaarsfacpub

Sobolev, Victor S.; Walk, Travis; Arias, Renee; Massa, Alicia; and Lamb, Marshall, "Inhibition of Aflatoxin Formation in Aspergillus Species by Peanut (Arachis hypogaea) Seed Stilbenoids in the Course of Peanut- Fungus Interaction" (2019). Publications from USDA-ARS / UNL Faculty. 2201.

https://digitalcommons.unl.edu/usdaarsfacpub/2201

This Article is brought to you for free and open access by the U.S. Department of Agriculture: Agricultural Research Service, Lincoln, Nebraska at DigitalCommons@University of Nebraska - Lincoln. It has been accepted for inclusion in Publications from USDA-ARS / UNL Faculty by an authorized administrator of DigitalCommons@University of Nebraska - Lincoln. 


\title{
Inhibition of Aflatoxin Formation in Aspergillus Species by Peanut (Arachis hypogaea) Seed Stilbenoids in the Course of Peanut- Fungus Interaction
}

\author{
Victor Sobolev,*ib Travis Walk, Renee Arias, Alicia Massa, and Marshall Lamb
}

National Peanut Research Laboratory, Agricultural Research Service, United States Department of Agriculture, P.O. Box 509, Dawson, Georgia 39842, United States

Supporting Information

\begin{abstract}
Common soil fungi, Aspergillus flavus and Aspergillus parasiticus, are opportunistic pathogens that invade preharvest peanut seeds. These fungi often produce carcinogenic aflatoxins that pose a threat to human and animal health through food chains and cause significant economic losses worldwide. Detection of aflatoxins and further processing of crops are mandated to ensure that contaminated agricultural products do not enter food channels. Under favorable conditions, the fungus-challenged peanut seeds produce phytoalexins, structurally related stilbenoids, capable of retarding fungal development. The purpose of the present study was to evaluate the potential influence of peanut phytoalexins on fungal development and aflatoxin formation in the course of peanut-fungus interaction. The present research revealed that during such interaction, aflatoxin formation was completely suppressed in A. flavus and A. parasiticus strains tested, when low concentrations of spores were introduced to wounded preincubated peanuts. In most of the experiments, when fungal spore concentrations were 2 orders of magnitude higher, the spores germinated and produced aflatoxins. Of all experimental seeds that showed fungal growth, $57.7 \%$ were aflatoxin-free after $72 \mathrm{~h}$ of incubation. The research provided new knowledge on the aflatoxin/phytoalexin formation in the course of peanut-fungus interaction.
\end{abstract}

KEYWORDS: peanut, groundnut, Arachis hypogaea, phytoalexin, stilbenoid, arachidin, aflatoxin, aflatoxin inhibition, Aspergillus, Aspergillus flavus, Aspergillus parasiticus, norsolorinic acid

\section{INTRODUCTION}

Common soil fungi, Aspergillus flavus and Aspergillus parasiticus, are opportunistic pathogens that invade peanut seeds at different stages of their development. These fungi often produce highly toxic, carcinogenic aflatoxins, predominantly aflatoxin $\mathrm{B}_{1}(\mathbf{5}$, Figure 1), that pose a threat to human and animal health through food chains and cause significant economic losses worldwide. ${ }^{1-9}$

Under favorable temperature and adequate water activity level, fungal conidia, the asexual spores of a fungus, germinate and form hyphae, the branching filaments that form the mycelium of a fungus. The formation of hyphae occurs after absorption of water through the walls of fungal spores, activation of the cytoplasm, and nuclear division. Fungi obtain nutrients through the action of enzymes secreted into the substrate on/in which they grow. Components of the fermented substrate are absorbed directly through the entire surface of hyphal walls of a fungus. Further fungal development may or may not lead to the formation of its dedicated reproductive structures, conidial heads (Figure 2C,D). ${ }^{10,11}$ Aspergillus invasion triggers accumulation of numerous structurally related, biologically active prenylated stilbenoids in peanut, as a plant defense mechanism. ${ }^{12-25}$ These stilbenoids are considered peanut phytoalexins with antifungal properties and are an essential natural defensive factor in preharvest aflatoxin contamination. ${ }^{14,23,26}$ The positive role of stilbenoids as defensive compounds against Aspergillus in peanut has been evaluated in 2-year field experiments. ${ }^{27}$ Sufficient water content in seeds is crucial for efficient production of the phytoalexins. ${ }^{15,19}$ Several com- pounds, including caffeic acid and resveratrol, the compounds formed in peanut seeds, were demonstrated to reduce aflatoxin production in peanut with or without affecting Aspergillus growth and normal mycelial development. ${ }^{28-31}$ A significant reduction or virtually complete suppression of aflatoxin production was revealed when selected Aspergillus toxigenic species were fed with major individual peanut stilbenoids, arachidin-1, arachidin-3, and chiricanine A, added to the growth medium. ${ }^{26}$ However, it was not clear whether fungal growth and aflatoxin inhibition by the de novo synthesized stilbenoids occurs in the course of peanut-fungus interaction.

The purpose of the present study was to evaluate the potential influence of peanut phytoalexins on Aspergillus development and aflatoxin formation in the course of peanut-fungus interaction.

\section{MATERIALS AND METHODS}

Reagents, Materials, and Basic Apparatus. HPLC-grade solvents used in the preparation of mobile phases and extractions of peanut seeds and fungal colonies were obtained from Fisher (Suwanee, GA). Formic acid (88\% ACS grade) was also purchased from Fisher. HPLC-grade $\mathrm{H}_{2} \mathrm{O}$ was prepared with a ZD20 four-bowl Milli-Q water system (Millipore).

Reference Compounds. Pure individual stilbenoids transarachidin-1 (1), trans-arachidin-2, trans-arachidin-3 (2), and trans-3'-

Received: March 29, 2019

Revised: May 15, 2019

Accepted: May 17, 2019

Published: May 17, 2019 
<smiles>CC(C)/C=C/c1c(O)cc(/C=C/c2ccc(O)c(O)c2)cc1O</smiles><smiles>CC(C)/C=C/c1c(O)cc(/C=C/c2ccc(O)cc2)cc1O</smiles><smiles>C=C(C)C=Cc1cc(C=Cc2cc(O)cc(O)c2)ccc1O</smiles><smiles>CC(C)/C=C/c1c(O)cc(/C=C/C2=CC(=O)OC2CC(=O)O)cc1O</smiles><smiles>COc1cc2c(c3oc(=O)c4c(c13)CCC4=O)C1C=COC1O2</smiles><smiles>CCCCCC(=O)c1c(O)cc2c(c1O)C(=O)c1c(O)cc(O)cc1C2=O</smiles>

Figure 1. Structures of major peanut prenylated polyphenolic compounds, aflatoxin $\mathrm{B}_{1}$, and norsolorinic acid: 1, trans-arachidin-1; 2, trans-arachidin-3; 3, trans-3' ${ }^{\prime}$-isopentadienyl-3,5, $4^{\prime}$-trihydroxystilbene; 4, SB-1; 5 , aflatoxin $\mathrm{B}_{1} ; 6$, norsolorinic acid.

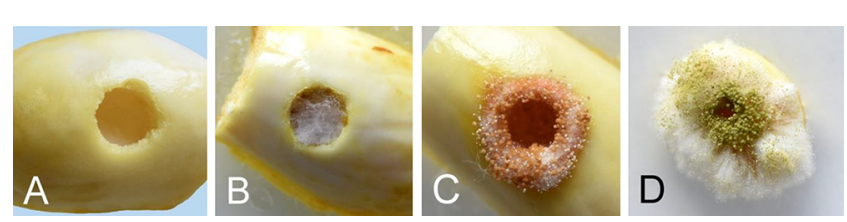

Figure 2. Wounded peanut seeds with typical levels of fungal colonization after $72 \mathrm{~h}$ of incubation at $30^{\circ} \mathrm{C}$ : plate $\mathrm{A}$, control seeds without fungus and experimental seeds without any signs of fungal infection; plate B, experimental seeds with fugal mycelium $A$. flavus NRRL 3357 retained within the drilled hole; plate C, experimental seeds with moderate-to-heavy fungal colonies of $A$. parasiticus NRRL 6111 showing orange conidial heads and mycelium structures; plate D, experimental seeds with heavy fungal colonies of A. flavus NRRL 3357 showing green conidial heads and white mycelium structures. All peanut seeds with the fungal colonization levels shown in plates $B-D$ were marked as seeds with fungal growth in Table 1 and were not subjected to smudging.

isopentadienyl-3,5,4'-trihydroxystilbene (IPD) (3) (Figure 1) were obtained as described ${ }^{18}$ except that preparative HPLC was used as a final purification step rather than preparative TLC. The separations were performed using a $100 \mathrm{~mm} \times 19 \mathrm{~mm}$ i.d., $5 \mu \mathrm{m}$ XTerra Prep RP18 OBD column (Waters); the column temperature was $40{ }^{\circ} \mathrm{C}$. The isocratic mobile phase used was composed of $55 \% \mathrm{CH}_{3} \mathrm{CN}$, 3\% of $2 \%$ $\mathrm{HCOOH}$ in $\mathrm{H}_{2} \mathrm{O}$, and $42 \%$ of $\mathrm{H}_{2} \mathrm{O}$; the flow rate was $8.0 \mathrm{~mL} / \mathrm{min}^{25}$ Chiricanine A was prepared as described. ${ }^{25}$ SB-1 (4) was obtained according to the described procedure. ${ }^{32}$ Aflatoxins $B_{1}$ (5, Figure 1), $B_{2}$, $G_{1}$, and $G_{2}$ were purchased from Sigma. Norsolorinic acid ( $98 \%$ pure) (6, Figure 1) was made available from the secondary fungal metabolite collection of the National Peanut Research Laboratory, ARS, USDA (Dawson, GA). The identities of the reference compounds were confirmed by APCI-MS/MS ( $\left.\mathrm{MS}^{2}\right)$ and UV spectroscopy (the equipment used is listed in the HPLC-DAD-MS Analysis section). These data are given in parentheses as $[\mathrm{M}+\mathrm{H}]^{+}$values followed by $\mathrm{UV}$ absorption maxima wavelengths: trans-resveratrol $(\mathrm{m} / z 229 ; 305$ and $317 \mathrm{~nm})$, trans-arachidin-1 (1) $(\mathrm{m} / z$ 313; $339 \mathrm{~nm})$, trans-arachidin-2 $(\mathrm{m} / z 297 ; 308$ and $322 \mathrm{~nm})$, trans-arachidin-3 $(2)(\mathrm{m} / z 297 ; 335 \mathrm{~nm})$, IPD (3) $(m / z 295 ; 295 \mathrm{~nm})$, SB-1 (4) $(\mathrm{m} / z 345 ; 363 \mathrm{~nm})$, chiricanine A $(m / z 281 ; 311 \mathrm{~nm})$, chiricanine B $(\mathrm{m} / z 297 ; 234,301$, and $311 \mathrm{~nm})$, arahypin-1 $(\mathrm{m} / z 281 ; 328 \mathrm{~nm})$, arahypin- $2(\mathrm{~m} / z$ 331; 306 and 317 $\mathrm{nm})$, arahypin-3 $(\mathrm{m} / z 331 ; 306$ and $320 \mathrm{~nm})$, arahypin-4 $(\mathrm{m} / z 315$; $311 \mathrm{~nm})$, arahypin-5 $(\mathrm{m} / z 295 ; 233,267$, and $334 \mathrm{~nm})$, arahypin- $6(\mathrm{~m} /$ $z$ 607; 272 and $340 \mathrm{~nm})$, arahypin-7 $(\mathrm{m} / z 623 ; 271$ and $347 \mathrm{~nm})$, arahypin-10 $(\mathrm{m} / z 295 ; 230,274$, and $315 \mathrm{~nm})$, arahypin-13 $(\mathrm{m} / z 279$; 230, 274, and $315 \mathrm{~nm})$, arahypin-14 $(\mathrm{m} / z 313 ; 236$ and $305 \mathrm{~nm})$, arahypin-15 $(\mathrm{m} / z 313 ; 229,307$, and $321 \mathrm{~nm})$. The above results were in agreement with published data. ${ }^{33}$

Fungal Material. The fungi used included three strains of Aspergillus that differed from each other by their aflatoxigenic potential: A. flavus NRRL 29487, a high aflatoxin producer; A. flavus NRRL 3357, a moderate aflatoxin producer; A. parasiticus NRRL 6111 (color mutant), a norsolorinic acid and low aflatoxin producer. The strains, as well as the information on the fungal toxigenic potential, were made available from the fungal collection and the database of the National Peanut Research Laboratory (NPRL), ARS, USDA (Dawson, GA).

The strains were grown on potato-dextrose agar (PDA) medium for 6 days at $29^{\circ} \mathrm{C}$ under luminescent light to promote conidia formation. The spores of each isolate were harvested by adding $10 \mathrm{~mL}$ of water with Tween 20 (two drops/L) and filtering through glass-fiber wool. Concentrations of spores in the suspension was determined with the help of a Scientific Hemocytometer (Fisher, cat. \#02-671-52B). The spore suspension was diluted with distilled sterile $\mathrm{H}_{2} \mathrm{O}$ to the needed concentrations of $1.7 \times 10^{3} / \mathrm{mL}, 1.7 \times 10^{4} / \mathrm{mL}$, and $1.7 \times 10^{5} / \mathrm{mL}$. Prepared spore suspensions were used for the experiments without delay. At the time of application, spores were maintained suspended with the help of a mini Teflon-coated magnetic stirrer. To ensure the viability of fungal spores, $3 \mu \mathrm{L}$ of spore suspension from each dilution vial, e.g., 5, 50, and 500 spores, were applied in the marked square sections of a PDA agar Petri plate (Figure 3A). The photo shows growth of the A. parasiticus NRRL 6111 isolate in all marked sections of the plate after incubation at $30^{\circ} \mathrm{C}$ for $72 \mathrm{~h}$.

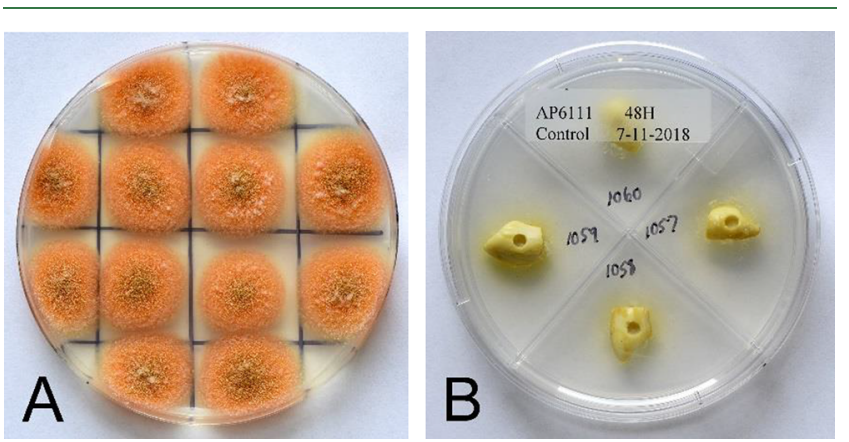

Figure 3. Plate $\mathrm{A}$, at the beginning of the experiment, $3 \mu \mathrm{L}$ of spore suspension from each dilution vial, e.g., 5, 50, and 500 spores, was applied in the middle of a marked square section of a PDA agar Petri dish. The number of marked sections (288) was equal to the number of seeds that received fungal spores. The photo shows the growth of the $A$. parasiticus NRRL 6111 isolate in all marked sections of the plate after incubation at $30^{\circ} \mathrm{C}$ for $72 \mathrm{~h}$. Similar growth was observed for all spore concentrations of all fungal isolates tested. Plate B, wounded seeds on water agar incubated at $30^{\circ} \mathrm{C}$ for $48 \mathrm{~h}$ (control). 


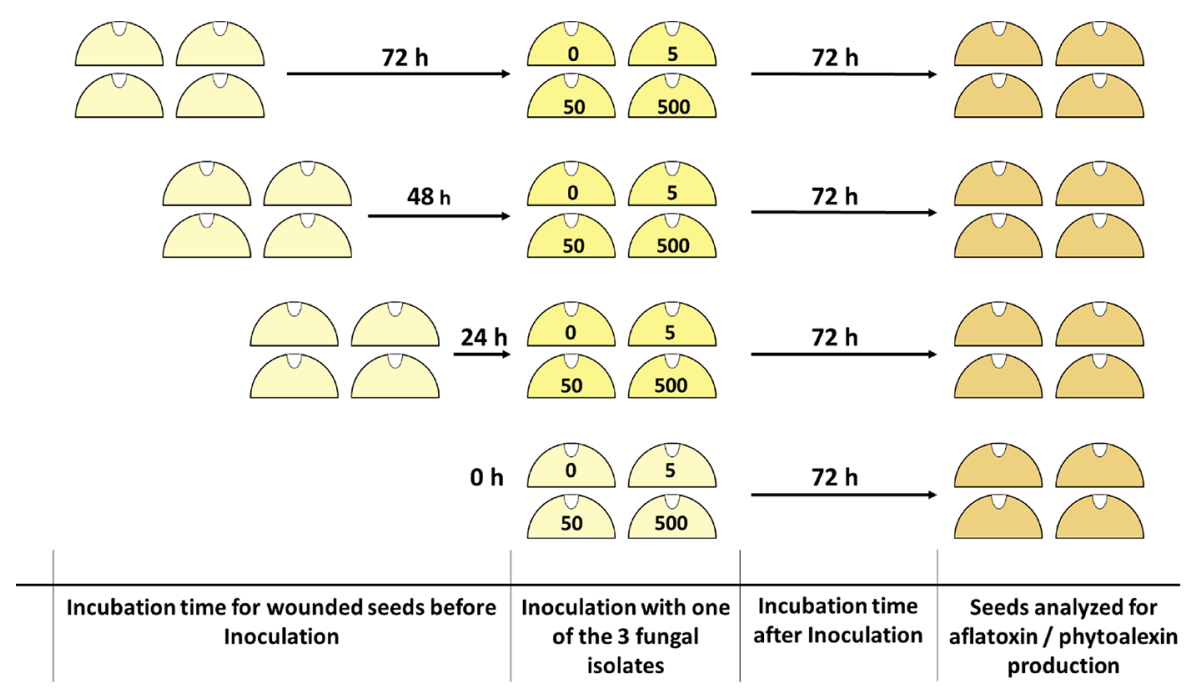

Each icon represents 8 biological replicates; values inside show the number of fungal spores applied to each of the 8 replicates

Figure 4. Flowchart of the experimental setup for the elucidation of changes in aflatoxin and phytoalexin formation in the course of peanut-fungus interaction for each of the Aspergillus species tested.

Plant Material. Viable seeds of a popular Georgia-O6G peanut cultivar (harvested in 2017) with acceptable disease resistance were chosen for the research. The nondestructive hull-scrape method was used to determine the maturity of the pods. ${ }^{34}$ Only seeds from brown and black mature pods were used.

Experimental Setup. Peanut pods were manually cracked, and whole seeds with skins were surface sterilized as described, ${ }^{35}$ but with some changes to the procedure. In brief, the seeds were submersed for 5 min in $75 \%$ ethanol followed by $5 \mathrm{~min}$ in $1 \%$ sodium hypochlorite ( $\mathrm{NaClO}$ ), rinsed once with sterile distilled $\mathrm{H}_{2} \mathrm{O}$, and sterilized one more time for $5 \mathrm{~min}$ in $1 \% \mathrm{NaClO}$ followed by rinsing four times with sterile distilled $\mathrm{H}_{2} \mathrm{O}$. Then the seeds were placed in a beaker with sterile distilled $\mathrm{H}_{2} \mathrm{O}$ and left for $16 \mathrm{~h}$ at $23 \pm 2{ }^{\circ} \mathrm{C}$ without light. The next day the seeds were rinsed with sterile $\mathrm{H}_{2} \mathrm{O}$ twice. The skins were removed from the seeds by gloved hands under axenic conditions. The deskinned seeds were manually separated into cotyledons. The embryos were removed by hand, and $3 \mathrm{~mm}$ of the cotyledon from the embryo side was cut off with a scalpel. Then, with the help of a $3 \mathrm{~mm}$ drill bit, a $2.5-3$ $\mathrm{mm}$ deep hole was made in the middle of the outer surface of the seed (Figure 2A). After that, the seeds were additionally sterilized for $10 \mathrm{~s}$ in $75 \% \mathrm{EtOH}$ and rinsed with $\mathrm{H}_{2} \mathrm{O}$ twice. Then the seeds were placed on a sterile paper towel, blotted, and allowed to dry under laminar flow for 2 min. The seeds were placed on Difco (BD, Franklin Lakes, NJ) 1.5\% water agar in Fisher $100 \times 15 \mathrm{~mm}$ compartmentalized Petri quad plates (Figure 3B). Each sector of the plate accommodated one seed on 6.5 $\mathrm{mL}$ of solidified agar. A total of 384 seeds were divided into 3 groups; 128 seeds were used for experiments with each fungal strain. According to the setup (Figure 4), each group of 128 seeds was subdivided into 4 groups, 32 seeds in each. Two Petri dishes with four seeds each served as eight biological replicates per test. In addition, 8 original dry seeds and 22 seeds hydrated for $16 \mathrm{~h}$ were used as controls. These seeds were kept frozen at $-80{ }^{\circ} \mathrm{C}$ before the aflatoxin and phytoalexin analysis.

After incubation at $30{ }^{\circ} \mathrm{C}$ for $0,24,48$, or $72 \mathrm{~h}$ (Figure 4), all experimental seeds in each group were inoculated on the same day with $0,5,50$, and 500 fungal spores by applying $3 \mu \mathrm{L}$ of the appropriate spore concentration to the bottom of the drilled hole (Figure $2 \mathrm{~A}$ ). Inoculated seeds were further incubated at $30{ }^{\circ} \mathrm{C}$ without light for $72 \mathrm{~h}$. Each cotyledon after incubation was visually rated for fungal colonization and photographed. Seeds that did not show fungal growth were cut into two pieces through the center of the hole, and each half of a cotyledon was smudged five or six times along a PDA-agar plate (one plate per cotyledon) so that agar touched the inside walls of the drilled hole (Figure $5 \mathrm{~A}-\mathrm{C}$ ). To prevent potential bacterial growth, the PDA
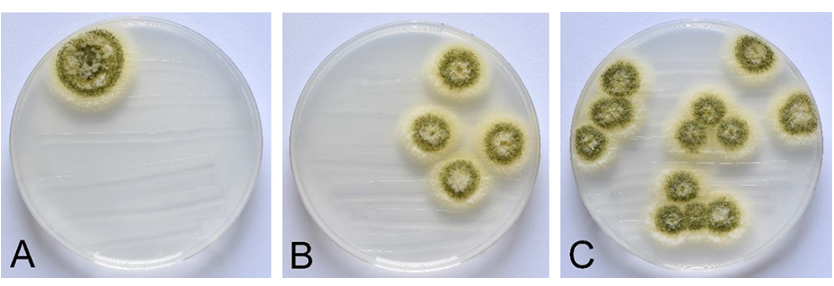

Figure 5. Petri dishes with five or six "smudges" made from side-to-side on PDA agar with single experimental cotyledons (one cotyledon per one Petri dish) that did not show any signs of fungal growth after incubation for $72 \mathrm{~h}$ at $30{ }^{\circ} \mathrm{C}$ : plate $\mathrm{A}$, smudges were made with cotyledons with 5 spores initially applied to the seed wound; plate B, 50 spores; plate $\mathrm{C}, 500$ spores.

medium was impregnated with the antibiotics carbenicillin and kanamycin, 100 and $50 \mathrm{mg} / \mathrm{L}$, respectively. After smudging, each cotyledon was placed into a preweighed $2 \mathrm{~mL}$ Bead Raptor vial (reinforced polypropylene with a silicon O-ring) vial with six $2.8 \mathrm{~mm}$ ceramic beads (both from Omni International, Inc., Kennesaw, GA) and kept frozen at $-80^{\circ} \mathrm{C}$ before the analysis. To extract aflatoxins and phytoalexins, $0.7 \mathrm{~mL}$ of $\mathrm{MeOH}$ was added to each vial, and the sample was pulverized in an Omni Bead Raptor 24 (Omni International, Inc., Kennesaw, GA) for $20 \mathrm{~s}$. Then the vials were centrifuged in a model 6765 Corning LSE Mini microcentrifuge (Corning, Inc., Tewksbury, MA) for $5 \mathrm{~min}$, and the supernatant was filtered through a Pasteur pipet with a glass-fiber plug firmly placed in its tip into a Thermo screw thread autosampler vial (catalog \# 03-375-17CA) with a matching cap (catalog \# 03-397-05). For aflatoxin analysis, $100 \mu \mathrm{L}$ of the filtrate was transferred into a Waters UPLC $700 \mu \mathrm{L}$ polypropylene $12 \times 32 \mathrm{~mm}$ vial (catalog \# 186005221) preloaded with $300 \mu \mathrm{L}$ of $\mathrm{MeOH}$, vortexed for 5 $\mathrm{s}$, and subjected to analysis by UPLC. Phytoalexins in the extract were analyzed by HPLC/MS without dilution.

HPLC-DAD-MS Analysis. Separations of the seed extracts were performed using a tandem HPLC-MS Surveyor system equipped with MS Pump Plus, Autosampler Plus, a PDA Plus Detector (Thermo Electron Corp., San Jose, CA) covering the $210-600 \mathrm{~nm}$ range, and a $100 \mathrm{~mm} \times 4.6 \mathrm{~mm}$ i.d., $3.5 \mu \mathrm{m}$ XSelect HSS C18 analytical column (Waters). $\mathrm{H}_{2} \mathrm{O}(\mathrm{A}), \mathrm{MeOH}(\mathrm{B})$, and $2 \% \mathrm{HCOOH}$ in $\mathrm{H}_{2} \mathrm{O}(\mathrm{C})$ were used in the following gradient: initial conditions, $59 \% \mathrm{~A} / 40 \% \mathrm{~B} / 1 \% \mathrm{C}$, changed linearly to $10 \% \mathrm{~A} / 89 \% \mathrm{~B} / 1 \% \mathrm{C}$ in $11 \mathrm{~min}$, changed to $0 \% \mathrm{~A} /$ $99 \% \mathrm{~B} / 1 \% \mathrm{C}$ in $0.01 \mathrm{~min}$, held isocratic for $3 \mathrm{~min}$, and then changed to initial conditions in $0.01 \mathrm{~min}$ and held for $4 \mathrm{~min}$ before the next 
injection. The flow rate was $1.2 \mathrm{~mL} / \mathrm{min}$. The column was maintained at $40{ }^{\circ} \mathrm{C}$. MS analysis was performed using a Finnigan LCQ Advantage MAX ion trap mass spectrometer equipped with an APCI interface and operated with Xcalibur version 1.4 software (Thermo Electron Corp., San Jose, CA). The data were acquired in the full-scan mode (MS) from $\mathrm{m} / z 100$ to 1000 . The heated capillary temperature was $250^{\circ} \mathrm{C}$, APCI vaporizer temperature $380{ }^{\circ} \mathrm{C}$, sheath gas flow 60 units, auxiliary gas flow 5 units, capillary voltage $53 \mathrm{~V}$, and source voltage $4.5 \mathrm{kV}$. In MS ${ }^{2}$ analysis, the $[\mathrm{M}+\mathrm{H}]^{+}$ions observed for each chromatographic peak in full-scan analysis were isolated and subjected to source collisioninduced dissociation (CID) using He buffer gas. In all CID analysis, the isolation width, relative fragmentation energy, relative activation $\mathrm{Q}$, and activation time were $1.4,30$ or $35 \%, 0.25$, and $30 \mathrm{~ms}$, respectively. Concentrations of all identified stilbenoids in the extracts were calculated by reference to peak areas (calibration curves) of corresponding pure standards at their UV absorption maxima or based on their published coefficients of molar extinction. ${ }^{33}$ Other stilbenoids were suggested to have the same coefficient of molar extinction as arachidin-1 (1). Their concentrations throughout the text, expressed in $\mathrm{mg} / \mathrm{g}$, are given for the comparison purpose only and may not represent the true concentrations of these compounds.

Aflatoxin Analysis. Extracts of peanut cotyledons were prepared as described above and subjected to aflatoxin analysis using a Waters Acquity UPLC instrument equipped with a matching UPLC H-class Quaternary Solvent Manager, UPLC Sample Manager, UPLC Fluorescent Detector (FLR), and an Acquity UPLC BEH C18 2.1 $\mathrm{mm} \times 100 \mathrm{~mm}, 1.7 \mu \mathrm{m}$ column. The mobile phase was composed of a water $/ \mathrm{MeOH} / \mathrm{CH}_{3} \mathrm{CN}(64: 22: 14, \mathrm{v} / \mathrm{v} / \mathrm{v})$ mixture, and the flow rate was $0.3 \mathrm{~mL} / \mathrm{min}$. The column was maintained at $40{ }^{\circ} \mathrm{C}$ in the system column heater. The excitation and emission wavelengths used for aflatoxin quantification were 362 and $435 \mathrm{~nm}$, respectively. Concentrations of aflatoxins were determined by reference to peak areas of corresponding commercial standards (calibration curve). The detection limit for aflatoxins $G_{1}$ and $B_{1}$ was 0.15 and $0.02 \mathrm{ng} / \mathrm{g}$ for aflatoxins $\mathrm{G}_{2}$ and $\mathrm{B}_{2}$.

Aflatoxin analysis in fungal colonies growing on smudged plates (Figure $5 \mathrm{~A}-\mathrm{C}$ ) was performed as described ${ }^{36}$ with the exception of using $\mathrm{MeOH}$ instead of a $\mathrm{MeOH}-\mathrm{H}_{2} \mathrm{O}$ mixture for the extraction of fungal colonies. The colonies were cut with a spatula and extracted with $\mathrm{MeOH}$ followed by purification on a minicolumn packed with basic aluminum oxide.

Statistical Analysis. Spearman's rank correlation coefficients were calculated and plotted using the corrplot $\mathrm{R}$ package. ${ }^{37}$ Analysis of variance was performed on raw or transformed variables, and means were compared using the Tukey test. All statistical analysis was conducted in $\mathrm{R}$ software. ${ }^{38}$

\section{RESULTS AND DISCUSSION}

Our previous research demonstrated a significant reduction in aflatoxin production, when selected Aspergillus toxigenic species were fed with major peanut stilbenoids added to the growth medium. ${ }^{26}$ On the basis of these findings, inhibition of aflatoxin formation in Aspergillus species by live peanut seeds was suggested. The complexity of the peanut seed-Aspergillus interaction in the field proposes the use of laboratory experimental models with both living organisms interacting under preset controlled conditions.

After preliminary trials of three experimental setups, including those previously used at the NPRL, ${ }^{22,35}$ we chose a new setup with precisely wounded peanut seeds (Figure 2A) placed on non-nutritious agar (Figure 3B). Water agar was used to maintain a sufficient moisture level favorable for the seed physiology throughout the experiment, and a drilled cavity allowed for a compact area for spore application and provided a sufficiently humid environment for the applied spores.

The experimental flowchart is presented in Figure 4. Peanut seeds need some time to produce phytoalexins in response to
Table 1. Frequency of Fungal Infection and Aflatoxin Production as the Outcome of Peanut-Fungus Interaction after $72 \mathrm{~h}$ of Incubation at $30^{\circ} \mathrm{C}$

\begin{tabular}{|c|c|c|c|c|}
\hline $\begin{array}{l}\text { time before } \\
\text { inoculation } \\
\text { (h) }\end{array}$ & $\begin{array}{l}\text { number } \\
\text { of } \\
\text { spores }\end{array}$ & $\begin{array}{l}\text { total } \\
\text { number of } \\
\text { seeds }^{a}\end{array}$ & $\begin{array}{l}\text { number of seeds } \\
\text { with fungal growth } \\
(\%)\end{array}$ & $\begin{array}{l}\text { number of seeds } \\
\text { with aflatoxin } B_{1} \\
(\%)\end{array}$ \\
\hline \multicolumn{5}{|c|}{ A. flavus NRRL 29487} \\
\hline 72 & 5 & 8 & $3(37.5)$ & $0(0.0)$ \\
\hline 72 & 50 & 8 & $7(87.5)$ & $0(0.0)$ \\
\hline 72 & 500 & 8 & $8(100.0)$ & $0(0.0)$ \\
\hline 48 & 5 & 8 & $6(75.0)$ & $0(0.0)$ \\
\hline 48 & 50 & 8 & $5(62.5)$ & $1(12.5)$ \\
\hline 48 & 500 & 8 & $8(100.0)$ & $5(62.5)$ \\
\hline 24 & 5 & 8 & $6(75.0)$ & $2(25.0)$ \\
\hline 24 & 50 & 8 & $8(100.0)$ & $5(62.5)$ \\
\hline 24 & 500 & 8 & $8(100.0)$ & $8(100.0)$ \\
\hline 0 & 5 & 8 & $8(100.0)$ & $8(100.0)$ \\
\hline 0 & 50 & 8 & $8(100.0)$ & $6(75.0)$ \\
\hline 0 & 500 & 7 & $7(100.0)$ & $7(100.0)$ \\
\hline \multicolumn{5}{|c|}{ A. flavus NRRL 3357} \\
\hline 72 & 5 & 8 & $1(12.5)$ & $0(0.0)$ \\
\hline 72 & 50 & 8 & $3(37.5)$ & $0(0.0)$ \\
\hline 72 & 500 & 8 & $3(37.5)$ & $1(12.5)$ \\
\hline 48 & 5 & 8 & $2(25.0)$ & $0(0.0)$ \\
\hline 48 & 50 & 8 & $8(100.0)$ & $3(37.5)$ \\
\hline 48 & 500 & 8 & $8(100.0)$ & $1(12.5)$ \\
\hline 24 & 5 & 8 & $2(25.0)$ & $0(0.0)$ \\
\hline 24 & 50 & 8 & $8(100.0)$ & $3(37.5)$ \\
\hline 24 & 500 & 8 & $8(100.0)$ & $2(25.0)$ \\
\hline 0 & 5 & 8 & $7(87.5)$ & $5(62.5)$ \\
\hline 0 & 50 & 8 & $8(100.0)$ & $8(100.0)$ \\
\hline 0 & 500 & 8 & $8(100.0)$ & $7(87.5)$ \\
\hline \multicolumn{5}{|c|}{ A. parasiticus NRRL 6111} \\
\hline 72 & 5 & 8 & $0(0.0)$ & $0(0.0)$ \\
\hline 72 & 50 & 8 & $2(25.0)$ & $1(12.5)$ \\
\hline 72 & 500 & 8 & $5(62.5)$ & $1(12.5)$ \\
\hline 48 & 5 & 8 & $3(37.5)$ & $2(25.0)$ \\
\hline 48 & 50 & 8 & $1(12.5)$ & $0(0.0)$ \\
\hline 48 & 500 & 8 & $6(75.0)$ & $2(25.0)$ \\
\hline 24 & 5 & 8 & $1(12.5)$ & $1(12.5)$ \\
\hline 24 & 50 & 8 & $8(100.0)$ & $5(62.5)$ \\
\hline 24 & 500 & 8 & $6(75.0)$ & $0(0.0)$ \\
\hline 0 & 5 & 8 & $5(62.5)$ & $0(0.0)$ \\
\hline 0 & 50 & 8 & $8(100.0)$ & $0(0.0)$ \\
\hline 0 & 500 & 8 & $8(100.0)$ & $1(12.5)$ \\
\hline \multicolumn{4}{|c|}{ total number of seeds $(\%)$} & $287(100)$ \\
\hline \multicolumn{4}{|c|}{ number of seeds with fungal growth (\% of total) } & $201(70.0)$ \\
\hline \multicolumn{4}{|c|}{$\begin{array}{l}\text { number of seeds with aflatoxin B1 (\% of seeds with } \\
\text { fungal growth) }\end{array}$} & $85(42.3)$ \\
\hline
\end{tabular}

${ }^{a}$ Total number of seeds excluding controls, which were not inoculated with fungal spores and did not show the presence of aflatoxins. 


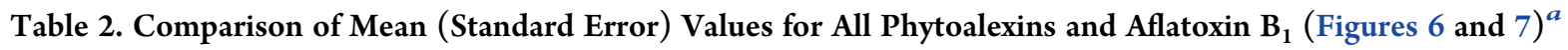

\begin{tabular}{|c|c|c|c|c|c|c|}
\hline & \multicolumn{5}{|c|}{ phytoalexins $(\mu \mathrm{g} / \mathrm{g})$} & \multirow[b]{2}{*}{$\mathrm{AFL} \mathrm{B}_{1}(\mathrm{ng} / \mathrm{g})$} \\
\hline & SB-1 & AR-1 & AR-3 & IPD & total & \\
\hline \multicolumn{7}{|c|}{ A. flavus NRRL 29487} \\
\hline \multicolumn{7}{|c|}{ Time $(\mathrm{h})$} \\
\hline 0 & $* 178.0$ a $(112.4)$ & $204.8 \mathrm{~b}(26.8)$ & $* 104.3$ a $(20.6)$ & $* 160.4$ a $(12.5)$ & $1139.0 \mathrm{ab}(100.1)$ & $* 4440.7$ a $(1194.1)$ \\
\hline 24 & $* 255.4$ a $(220.0)$ & 379.9 a $(33.2)$ & *52.4 ab (10.5) & $* 103.4 \mathrm{~b}(8.2)$ & $1309.1 \mathrm{a}(125.2)$ & $* 939.3$ b (538.3) \\
\hline 48 & $* 130.2 \mathrm{~b}(154.3)$ & 388.5 a $(22.0)$ & $* 33.3 \mathrm{~b}(5.8)$ & $* 51.7 \mathrm{~d}(5.2)$ & $945.9 \mathrm{~b}(92.8)$ & $* 159.5$ c $(81.1)$ \\
\hline 72 & $* 108.2 \mathrm{~b}(106.5)$ & 338.5 a $(27.0)$ & $* 45.6 \mathrm{ab}(6.4)$ & $* 62.9$ c $(3.8)$ & $933.0 \mathrm{~b}(87.7)$ & $* 0.0$ c $(0.0)$ \\
\hline \multicolumn{7}{|c|}{ Number of Spores } \\
\hline 0 & $* 0.0 \mathrm{c}(0.0)$ & $267.7 \mathrm{~b}(20.0)$ & $* 10.2 \mathrm{~b}(0.8)$ & $* 60.3 \mathrm{~b}(7.2)$ & 565.7 c $(54.7)$ & $* 0.0$ c $(0.0)$ \\
\hline 5 & $* 102.0 \mathrm{~b}(19.0)$ & $337.4 \mathrm{ab}(21.6)$ & *54.9 a (9.7) & *94.3 a (11.8) & $928.5 \mathrm{~b}(80.4)$ & $* 947.8 \mathrm{~b}(437.5)$ \\
\hline 50 & $* 227.8$ a $(24.6)$ & 361.7 a $(30.7)$ & $* 72.9$ a $(12.7)$ & $* 111.0$ a $(12.7)$ & 1323.9 a $(87.4)$ & $* 625.8 \mathrm{~b}(187.7)$ \\
\hline 500 & *292.6 a (29.7) & $337.9 \mathrm{ab}(39.8)$ & $* 78.8$ a $(15.2)$ & $* 95.9$ a $(7.5)$ & 1350.7 a $(111.8)$ & $* 3306.6$ a $(1142.2)$ \\
\hline \multicolumn{7}{|c|}{ A. flavus NRRL 3357} \\
\hline \multicolumn{7}{|c|}{ Time $(\mathrm{h})$} \\
\hline 0 & $* * 185.3$ a $(28.2)$ & 290.5 b (24.8) & $* 157.7$ a $(27.4)$ & *94.6 a $(8.9)$ & $* 1195.6$ a $(123.4)$ & $* 2334.0$ a $(630.9)$ \\
\hline 24 & $* * 177.2$ a $(31.6)$ & $326.0 \mathrm{ab}(22.0)$ & $* 101.6 \mathrm{ab}(23.2)$ & $* 72.6 \mathrm{ab}(6.4)$ & $* 1097.5$ a $(126.3)$ & $* 356.5 \mathrm{~b}(180.9)$ \\
\hline 48 & $* * 111.3 \mathrm{~b}(21.2)$ & 398.4 a $(27.6)$ & $* 113.9$ a $(21.4)$ & $* 55.6 \mathrm{bc}(4.3)$ & $* 1096.3$ a $(97.5)$ & $* 199.1$ b (105.5) \\
\hline 72 & $* * 72.0 \mathrm{c}(21.4)$ & 391.1 a $(28.7)$ & $* 59.2 \mathrm{~b}(16.8)$ & $* 51.1$ c $(4.3)$ & $* 913.5$ a $(88.0)$ & $* 42.4 \mathrm{~b}(42.4)$ \\
\hline \multicolumn{7}{|c|}{ Number of Spores } \\
\hline 0 & $* * 0.0 \mathrm{~d}(0.0)$ & 233.9 c (15.2) & $* 7.5$ c $(0.8)$ & $* 34.5$ c (3.4) & $* 447.4$ c $(33.9)$ & $* 0.0$ c $(0.0)$ \\
\hline 5 & $* * 55.1$ c $(12.0)$ & $335.6 \mathrm{~b}(20.4)$ & $* 49.6 \mathrm{~b}(8.9)$ & $* 65.0 \mathrm{~b}(5.8)$ & $* 801.1 \mathrm{~b}(49.4)$ & $* 383.6$ bc $(246.9)$ \\
\hline 50 & $* * 174.4 \mathrm{~b}(19.1)$ & $389.3 \mathrm{ab}(24.3)$ & $* 168.8$ a $(22.9)$ & $* 82.8 \mathrm{ab}(7.6)$ & $* 1328.3$ a $(82.8)$ & $* 1432.2$ a $(531.8)$ \\
\hline 500 & **293.9 a (26.1) & 421.3 a $(30.8)$ & $* 190.6$ a $(26.6)$ & $* 86.7$ a $(6.2)$ & $* 1615.8$ a $(106.5)$ & $* 1078.8 \mathrm{ab}(408.2)$ \\
\hline \multicolumn{7}{|c|}{ A. parasiticus NRRL 6111} \\
\hline \multicolumn{7}{|c|}{ Time $(\mathrm{h})$} \\
\hline 0 & $* 68.9$ a $(13.1)$ & $433.0 \mathrm{ab}(42.5)$ & $* 106.6$ a $(17.1)$ & $* 172.1$ a $(15.7)$ & $* 1300.2$ a $(125.1)$ & $* 131.2$ a $(131.2)$ \\
\hline 24 & $* 42.9 \mathrm{~b}(10.0)$ & 483.3 a $(37.7)$ & $* 127.0$ a $(26.3)$ & $* 77.6 \mathrm{~b}(6.0)$ & $* 1168.7 \mathrm{ab}(109.8)$ & $* 119.4$ a $(44.9)$ \\
\hline 48 & $* 21.9 \mathrm{~b}(5.1)$ & $393.6 \mathrm{~b}(25.5)$ & $* 68.8$ a $(14.1)$ & $* 84.8 \mathrm{~b}(11.5)$ & $* 887.7 \mathrm{~b}(77.1)$ & $* 76.6$ a $(47.2)$ \\
\hline 72 & $* 10.8$ c $(3.2)$ & $463.0 \mathrm{ab}(24.6)$ & $* 58.4$ a $(14.5)$ & $* 81.5 \mathrm{~b}(5.7)$ & $* 973.8 \mathrm{ab}(59.5)$ & $* 10.7$ a $(7.9)$ \\
\hline \multicolumn{7}{|c|}{ Number of Spores } \\
\hline 0 & $* 0.0 \mathrm{~d}(0.0)$ & 284.1 c $(38.1)$ & $* 11.1$ c $(3.7)$ & $* 88.1 \mathrm{~b}(13.0)$ & $* 647.0 \mathrm{c}(86.6)$ & $0.0 \mathrm{a}(0.0)$ \\
\hline 5 & $* 24.1$ c $(7.5)$ & $427.8 \mathrm{~b}(31.4)$ & $* 63.2 \mathrm{~b}(15.0)$ & $* 122.1$ a $(15.8)$ & $* 1047.8$ b $(106.3)$ & 52.0 a $(35.4)$ \\
\hline 50 & $* 38.5 \mathrm{~b}(5.7)$ & $481.9 \mathrm{ab}(26.3)$ & $* 121.2$ a $(21.4)$ & $* 102.9 \mathrm{ab}(10.2)$ & $* 1168.2 \mathrm{ab}(80.4)$ & 104.7 a (41.1) \\
\hline 500 & *79.8 a (13.2) & 556.0 a (26.3) & $* 151.5$ a $(17.9)$ & *104.3 ab (11.6) & *1399.3 a (81.5) & 168.2 a $(133.6)$ \\
\hline
\end{tabular}

${ }^{a}$ Means followed by the same letter in the same column are not significantly different $(p<0.05)$. Analysis of variance was performed on raw or transformed variables, log or square root, marked $*$ and $* *$, respectively, but the values are presented as raw values in the table. Abbreviations: AR1, trans-arachidin-1; AR-3, trans-arachidin-3; IPD, trans-3'-isopentadienyl-3,5,4'-trihydroxystilbene; AFL $B_{1}$, aflatoxin $B_{1}$.

exogenous stimuli. ${ }^{17,21,39}$ Therefore, wounded seeds were allowed up to $72 \mathrm{~h}$ of incubation (Figure 4) before exposing them to fungal spores, a stressful challenge that in most cases leads to increased production of stilbenoids. ${ }^{21,22,39}$ At the beginning of the experiment, $3 \mu \mathrm{L}$ of spore suspension from each dilution concentration, e.g., 5, 50, and 500 spores, was applied in marked sections of a PDA agar Petri dish (Figure 3A). The number of marked sections (288) was equal to the number of seeds that received fungal spores at matching concentrations. Figure 3A shows growth of the A. parasiticus NRRL 6111 isolate in all marked sections of the plate after incubation at $30^{\circ} \mathrm{C}$ for 72 h. Similar growth was observed for all spore concentrations of all fungal isolates tested. This fact demonstrates the viability of fungal spores used for each individual seed at the time of the experiment. After 3 and 5 days of incubation at $30^{\circ} \mathrm{C}$, some colonies of each fungus tested were cut with a spatula from the marked sections of a PDA agar, extracted with $\mathrm{MeOH}$, and purified. ${ }^{36}$ The extracts of all fungal isolates showed the presence of aflatoxins at levels proportional to their NPRL toxigenic ratings.

Wounded seeds demonstrated different responses to the fungal presence that varied with time of incubation before inoculation with spores, number of spores applied, and the nature of the fungal strain used (Figure 2A-D). Of particular interest were the experimental seeds that were observed under $30 \times$ magnification and did not show signs of fungal growth (Figure 2A). Apparently, spore germination was temporarily suppressed, or the spores' vitality was destroyed permanently by the defensive peanut compounds. In order to ensure the nonviability/viability of these spores, all the seeds were smudged on PDA agar as described in the Materials and Methods and incubated. Panels A, B, and C of Figure 5 show an example of incubated plates with smudges made with cotyledons with initial 5,50 , and 500 spores applied to the seed wound, respectively. Apparently, some fungal spores from cotyledons were transferred onto the agar and germinated. Some fungal colonies were cut from the plates and prepared as described above for the aflatoxin analysis. All of the tested fungal colonies showed the presence of aflatoxins at concentrations comparable to those obtained from the marked sections. The result of this experiment allows one to suggest that wounded peanut seeds obtain appreciable fungistatic activity. Table 1 shows that about one-third (30\%) of all experimental seeds did not demonstrate any visible fungal development. 

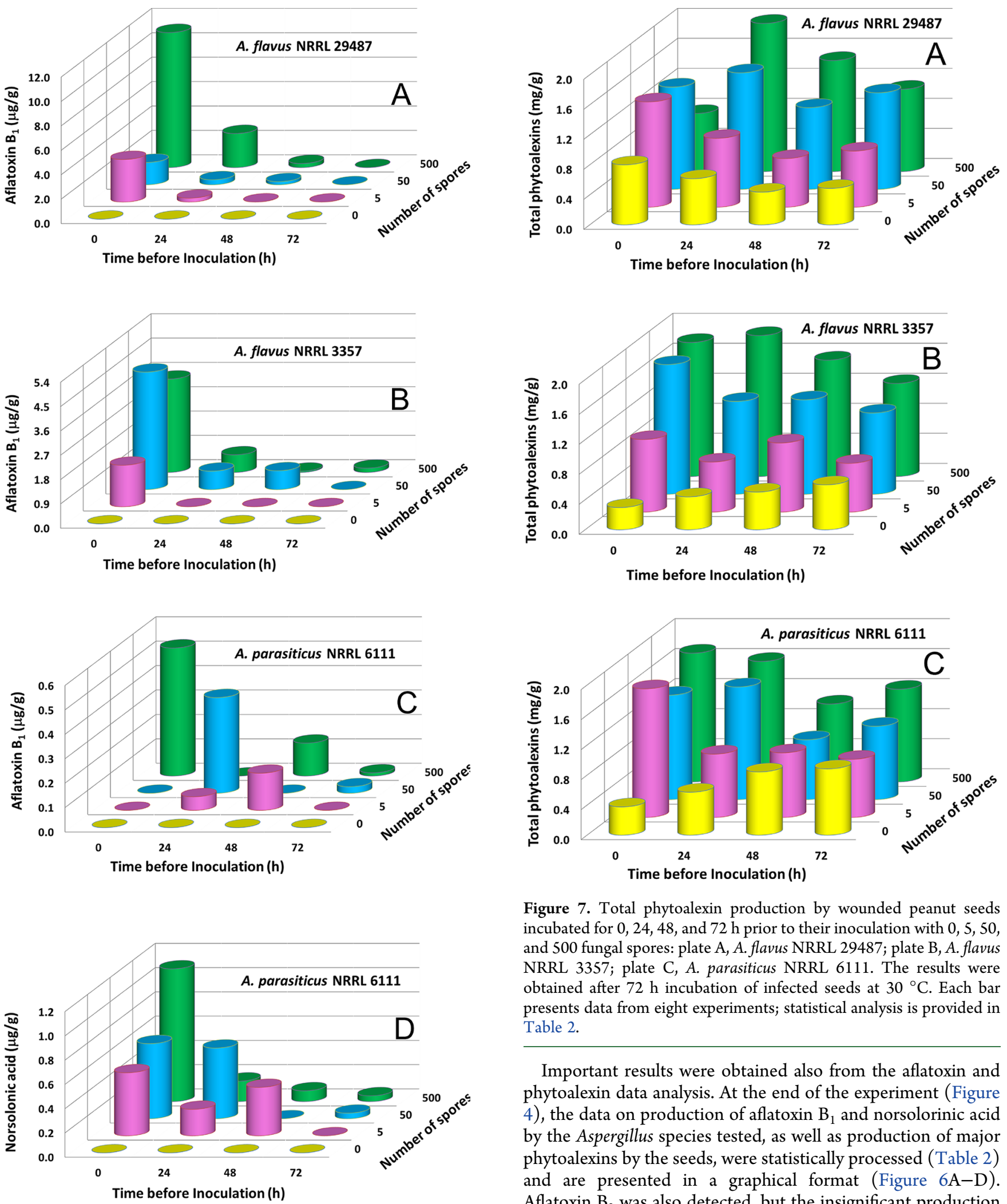

Figure 6. Production of aflatoxin $\mathrm{B}_{1}$ and norsolorinic acid by Aspergillus species applied to wounded peanut seeds $0,24,48$, and $72 \mathrm{~h}$ prior to their inoculation with $0,5,50$, and 500 fungal spores: plate A, A. flavus NRRL 29487; plate B, A. flavus NRRL 3357; plate C, A. parasiticus NRRL 6111; plate $D$, production of norsolorinic acid by $A$. parasiticus NRRL 6111. The results were obtained after $72 \mathrm{~h}$ of incubation of infected seeds at $30^{\circ} \mathrm{C}$. Each bar presents data from eight experiments; statistical analysis is shown in Table 2.

Figure 7. Total phytoalexin production by wounded peanut seeds incubated for $0,24,48$, and $72 \mathrm{~h}$ prior to their inoculation with $0,5,50$, and 500 fungal spores: plate A, A. flavus NRRL 29487; plate B, A. flavus NRRL 3357; plate C, A. parasiticus NRRL 6111. The results were obtained after $72 \mathrm{~h}$ incubation of infected seeds at $30^{\circ} \mathrm{C}$. Each bar presents data from eight experiments; statistical analysis is provided in Table 2 .

Important results were obtained also from the aflatoxin and phytoalexin data analysis. At the end of the experiment (Figure 4 ), the data on production of aflatoxin $B_{1}$ and norsolorinic acid by the Aspergillus species tested, as well as production of major phytoalexins by the seeds, were statistically processed (Table 2) and are presented in a graphical format (Figure 6A-D). Aflatoxin $\mathrm{B}_{2}$ was also detected, but the insignificant production of this toxin by the A. flavus strains and aflatoxins $\mathrm{B}_{2}$ and $\mathrm{G}_{2}$ by the $A$. parasiticus strain used in present research was not accounted here due to the simplicity of the presentation. Production of aflatoxin $B_{2}$ is shown in Figure $A$ of the Supporting Information.

Higher aflatoxin production by the strains positively correlated with higher spore concentration and negatively correlated with longer incubation time before spore application 


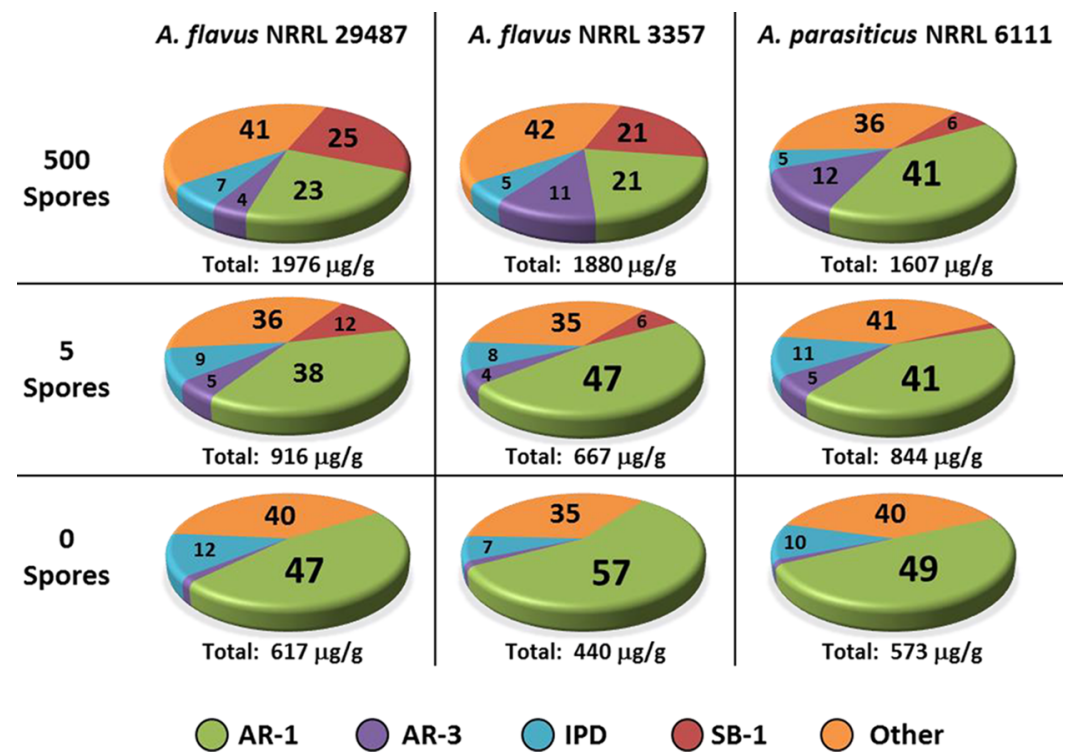

Figure 8. Phytoalexin composition in wounded seeds incubated for $24 \mathrm{~h}$ prior to application of different numbers of fungal spores. Abbreviations: AR1, trans-arachidin-1; AR-3, trans-arachidin-3; IPD, trans-3'-isopentadienyl-3,5,4'-trihydroxystilbene; other, all other stilbenoids. Each pie graph presents data from eight experiments; statistical analysis is provided in Table 2.
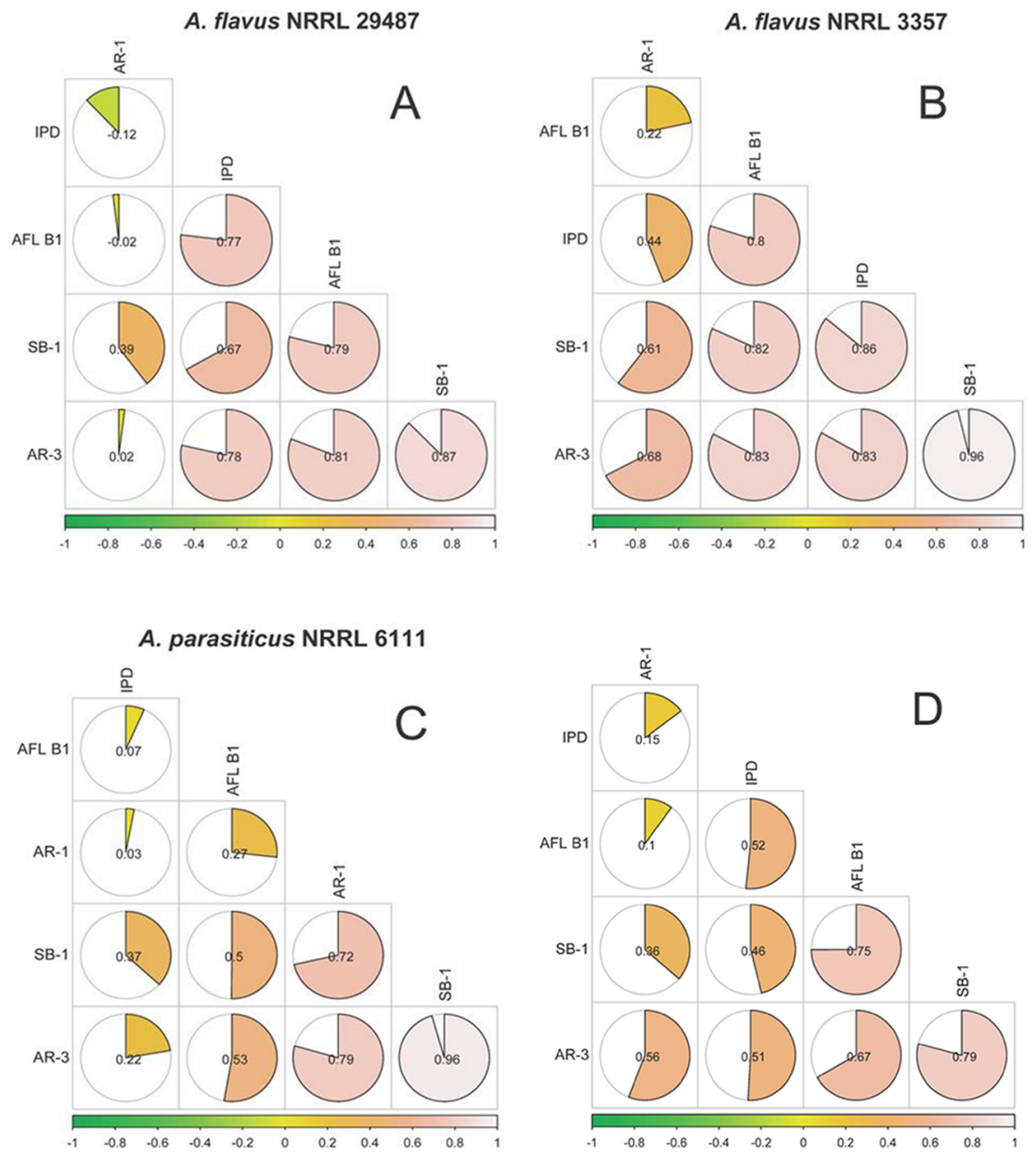

Figure 9. Correlograms demonstrate the correlation of a series of data obtained in the course of peanut-fungus interaction: plate A, with A. flavus NRRL 29487; plate B, with A. flavus NRRL 3357; plate C, with A. parasiticus NRRL 6111; plate D, shows combined data from the experiments with the three fungi. Abbreviations: AR-1, trans-arachidin-1; AR-3, trans-arachidin-3; IPD, trans-3'-isopentadienyl-3,5,4'-trihydroxystilbene; AFL B1, aflatoxin $\mathrm{B}_{1}$. 
(Figure 6A-C; Table 1). The same pattern was also observed for the first aflatoxin precursor, norsolorinic acid (6) (Figure $6 \mathrm{D})$. The highest levels and frequency of aflatoxin production were observed when seeds were inoculated with fungal spores immediately after wounding them. In contrast, after appreciable incubation time, particularly after $72 \mathrm{~h}$, aflatoxin and norsolorinic acid production was minimal or was completely suppressed (Figure 6A-D, Table 1, and Table A of the Supporting Information). Table A shows that in some experiments norsolorinic acid was produced by the $A$. parasiticus NRRL 6111 strain, while no aflatoxin production was detected in the same samples. We note, however, that the limited number of experiments does not allow one to make sound conclusions on the selective suppression of aflatoxin vs norsolorinic acid biosynthesis under the experimental conditions used.

Combined data, regardless of the fungal strains used, number of spores applied, and time of incubation before inoculation, demonstrate that of all the seeds that showed fungal growth, $57.7 \%$ were aflatoxin-free after $72 \mathrm{~h}$ of incubation (Table 1 ). Statistical comparison of mean values for aflatoxin $B_{1}$ is given in Table 2. The most significant difference in aflatoxin levels in the A. flavus NRRL 29487 and A. flavus NRRL 3357 was observed between 0 (no incubation time before spore inoculation) and longer incubation times, 24, 48, and $72 \mathrm{~h}$ (Table 2). This fact suggests the influence of peanut stilbenoids on the mechanism of plant-fungus interaction.

Total phytoalexin production by wounded peanut seeds at different incubation times and spore concentrations in response to fungal challenge is shown in Figure $7 \mathrm{~A}-\mathrm{C}$ and Table 2. With all three fungal isolates, a significant difference was most noticeable between the controls (no fungal spores) and the experimental seeds (Table 2). In contrast, in most of the experiments, there was no significant difference between total phytoalexin concentrations within the experimental time and the number of spores applied (Table 2). These data allow one to conclude that regardless of the toxigenic potential of the fungi tested and the concentrations of their spores that contact the seed wound, as well as the incubation time, overall phytoalexin production stays within insignificantly different limits (Table 2). However, there was a significant difference in the composition of individual stilbenoids (Figure 8 and Figure B of the Supporting Information). For example, after $24 \mathrm{~h}$ of incubation prior to spore application, arachidin-1 (1) was the predominant stibenoid in the extracts of individual control seeds, while SB1 (4) appeared only in the presence of growing fungi or fungal spores, and the ratio of $\mathbf{1}$ in the matrix was decreased in favor of 4 from the controls to seeds with higher number of spores, although application of only five fungal spores was sufficient to cause the formation of SB-1 (4). Orange sectors in the pie charts (Figure 8 and Figure B of the Supporting Information) represent the sum of other than listed (Figure 1) stilbenoids (Material and Methods).

The interrelationship between all experimental data is shown in Figure 9; the correlograms demonstrate the simultaneous change in value of all the variables obtained in the course of peanut-fungus interaction. The analysis of data correlation from all experiments with individual fungal isolates (Figure 9AC) as well as combined data correlation (Figure 9D) allows one to conclude, for example, that there was a strong positive correlation between aflatoxin $\mathrm{B}_{1}$, arachidin-3, IPD, and SB-1 in the experiments with A. flavus NRRL 29487 and A. flavus NRRL 3357. On the other hand, aflatoxin $B_{1}$ practically did not correlate with the major stilbenoid arachidin-1 (1) in all the experiments with A. flavus NRRL 29487 and moderately correlated with in the experiments with A. flavus NRRL 3357 and $A$. parasiticus NRRL 6111 (Figure 9A-C). Of particular interest is a very high correlation level between arachidin-3 (2) and SB-1 (4) in all experiments with all fungal isolates. Such a correlation may be attributed to a probable conversion of stilbenoid 2 into 4 through 1 within the time frame of the experiments, as earlier suggested. ${ }^{32}$ In agreement with our previous research, ${ }^{26}$ production of aflatoxin $B_{1}$ in some experiments did not necessarily positively correlate with the degree of fungal colonization of wounded seeds as apparent from Table A of the Supporting Information.

The present research demonstrated that in the course of peanut-fungus interaction, in the majority of experiments, aflatoxin production was suppressed in all fungi tested when lower concentrations of spores were applied to wounded seeds; with all fungi tested, higher concentrations of aflatoxin $\mathrm{B}_{1}(\mathbf{5})$ were produced with a higher concentration of spores and shorter incubation times before spore application; production patterns of aflatoxin $\mathrm{B}_{2}$ and the primary aflatoxin precursor, norsolorinic acid (6), were very similar to that of aflatoxin $\mathrm{B}_{1}$; of all experimental seeds that showed fungal growth, $57.7 \%$ were aflatoxin-free after $72 \mathrm{~h}$ of incubation; overall production of stilbenoids was not significantly different between experiments with different fungi tested; concentrations of stilbenoids in wounded peanuts increased with higher concentrations of spores contacting them; compared to the control, the composition of stilbenoids changed significantly upon interaction with fungal structures; phytoalexin profiles and production changed with incubation time before fungal application and the number of spores applied; formation of SB-1 (4) was observed only in the presence of fungal spores or actively growing fungi; arachidin-1 (1) was the predominant phytoalexin in all the experiments with the exception of the experiment with the most aggressive fungus, A. flavus NRRL 29487,500 spores used, and zero and $24 \mathrm{~h}$ of incubation before spore application.

\section{ASSOCIATED CONTENT}

\section{Supporting Information}

The Supporting Information is available free of charge on the ACS Publications website at DOI: 10.1021/acs.jafc.9b01969.

Figures showing the production of aflatoxin $\mathrm{B}_{2}$ by Aspergillus species and the phytoalexin composition in wounded seeds after the application of fungal spores (PDF)

\section{AUTHOR INFORMATION}

\section{Corresponding Author}

*Tel: +1 229995 7446. Fax: +1 229995 7416. E-mail: victor. sobolev@ars.usda.gov.

\section{ORCID}

Victor Sobolev: 0000-0001-5352-9539

\section{Funding}

This work was supported by USDA-ARS projects 6044-42000011-00D and 6604-21000-003-00D.

\section{Notes}

The authors declare no competing financial interest. 


\section{ABBREVIATIONS USED}

$\mathrm{DAD}$, diode array detector; HPLC, high-performance liquid chromatography; UPLC, ultra-performance liquid chromatography; MS, mass spectrometer, mass spectrometry, mass spectra; APCI-MS, atmospheric pressure chemical ionization mass spectrometry, mass spectrum

\section{REFERENCES}

(1) Williams, J. H.; Phillips, T. D.; Jolly, P. E.; Stiles, J. K.; Jolly, C. M.; Aggarwal, D. Human aflatoxicosis in developing countries: a review of toxicology, exposure, potential health consequences, and interventions. Am. J. Clin. Nutr. 2004, 80, 1106-1122.

(2) Althouse, R.; Huff, J.; Tomatis, L.; Wilbourn, J. An evaluation of chemicals and industrial processes associated with cancer in humans based on human and animal data: IARC Monographs Vol. 1 to 20. Cancer Res. 1980, 40, 1-12.

(3) Kew, M. C. Aflatoxins as a cause of hepatocellular carcinoma. J. Gastrointestin Liver Dis. 2013, 22, 305-310.

(4) Gong, Y. Y.; Egal, S.; Hounsa, A.; Turner, P. C.; Hall, A. J.; Cardwell, K. F.; Wild, C. P. Determinants of aflatoxin exposure in young children from Benin and Togo, West Africa: the critical role of weaning. Int. J. Epidemiol. 2003, 32, 556-562.

(5) Azziz-Baumgartner, E.; Lindblade, K.; Gieseker, K.; Rogers, H. S.; Kieszak, S.; Njapau, H.; Schleicher, R.; McCoy, L. F.; Misore, A.; DeCock, K.; Rubin, C.; Slutsker, L. and the Aflatoxin Investigative Group. Case-control study of an acute aflatoxicosis outbreak, Kenya, 2004. Environ. Health Perspect. 2005, 113, 1779-1783.

(6) Lye, M. S.; Ghazali, A. A.; Mohan, J.; Alwin, N.; Nair, R. C. An outbreak of acutehepatic encephalopathy due to severe aflatoxicosis in Malaysia. Am. J. Trop. Med. Hyg. 1995, 53, 68-72.

(7) Murugavel, K. G.; Naranatt, P. P.; Shankar, E. M.; Mathews, S.; Raghuram, K.; Rajasambandam, P.; Jayanthi, V.; Surendran, R.; Murali, A.; Srinivas, U.; Palaniswamy, K. R.; Srikumari, D.; Thyagarajan, S. P. Prevalence of aflatoxin $B_{1}$ in liver biopsies of proven hepatocellular carcinoma in India determined by an in-house immunoperoxidase test. J. Med. Microbiol. 2007, 56, 1455-1459.

(8) Wang, J. S.; Huang, T.; Su, J.; Liang, F.; Wei, Z.; Liang, Y.; Luo, H.; Kuang, S. Y.; Qian, G. S.; Sun, G.; He, X.; Kensler, T. W.; Groopman, J. D. Hepatocellular carcinoma and aflatoxin exposure in Zhuqing village, Fusui county, People's Republic of China. Cancer Epidemiol. Biomark. Prevent. 2001, 10, 143-146.

(9) Lamb, M. C.; Sternitzke, D. A. Cost of aflatoxin to the farmer, buying point, and sheller segments of the Southeast United States peanut industry. Peanut Sci. 2001, 28, 59-63.

(10) Hawker, L. E. The Physiology of Reproduction in Fungi, 1st ed.; Cambridge University Press: Cambridge, UK, 1957; 136 pp.

(11) Carlile, M. J.; Watkinson, S. C.; Gooday, G. W. The Fungi, 2nd ed.; Academic Press: London, UK, 2001, 603 pp.

(12) Keen, N. T.; Ingham, J. L. New stilbene phytoalexins from American cultivars of Arachis hypogaea. Phytochemistry 1976, 15, 1794-1795.

(13) Aguamah, G. A.; Langcake, P.; Leworthy, D. P.; Page, J. A.; Pryce, R. J.; Strange, R. N. Two novel stilbene phytoalexins from Arachis hypogaea. Phytochemistry 1981, 20, 1381-1383.

(14) Wotton, H. R.; Strange, R. N. Circumstantial evidence for phytoalexin involvement in the resistance of peanuts to Aspergillus flavus. Microbiology 1985, 131, 487-494.

(15) Wotton, H. R.; Strange, R. N. Increased susceptibility and reduced phytoalexin accumulation in drought-stressed peanut kernels challenged with Aspergillus flavus. Appl. Environ. Microbiol. 1987, 53, 270-273.

(16) Cooksey, C. J.; Garratt, P. J.; Richards, S. E.; Strange, R. N. A dienyl stilbene phytoalexin from Arachis hypogaea. Phytochemistry 1988, 27, 1015-1016.

(17) Arora, M. K.; Strange, R. N. Phytoalexin accumulation in groundnuts in response to wounding. Plant Sci. 1991, 78, 157-163.
(18) Sobolev, V. S.; Cole, R. J.; Dorner, J. W.; Yagen, B. Isolation, purification, and liquid chromatographic determination of stilbene phytoalexins in peanuts. J. AOAC Int. 1995, 78, 1177-1182.

(19) Dorner, J. W.; Cole, R. J.; Sanders, T. H.; Blankenship, P. D. Interrelationship of kernel water activity, soil temperature, maturity, and phytoalexin production in preharvest aflatoxin contamination of drought-stressed peanuts. Mycopathologia 1989, 105, 117-128.

(20) Sobolev, V. S.; Potter, T. L.; Horn, B. W. Prelylated stilbenes from peanut root mucilage. Phytochem. Anal. 2006, 17, 312-322.

(21) Sobolev, V. S. Production of phytoalexins in peanut (Arachis hypogaea) seed elicited by selected microorganisms. J. Agric. Food Chem. 2013, 61, 1850-1858.

(22) Sobolev, V. S. Localized production of phytoalexins by peanut (Arachis hypogaea) kernels in response to invasion by Aspergillus species. J. Agric. Food Chem. 2008, 56, 1949-1954.

(23) Sobolev, V. S.; Khan, S. I.; Tabanca, N.; Wedge, D. E.; Manly, S. P.; Cutler, S. J.; Coy, M. R.; Becnel, J. J.; Neff, S. A.; Gloer, J. B. Biological activity of peanut (Arachis hypogaea) phytoalexins andselected natural and synthetic stilbenoids. J. Agric. Food Chem. 2011, 59, 1673-1682.

(24) Sobolev, V. S.; Krausert, N. M.; Gloer, J. B. New monomeric stilbenoids from peanut (Arachis hypogaea) seeds challenged by an Aspergillus flavus strain. J. Agric. Food Chem. 2016, 64, 579-584.

(25) Sobolev, V. S.; Neff, S. A.; Gloer, J. B. New stilbenoids from peanut (Arachis hypogaea) seeds challenged by an Aspergillus caelatus strain. J. Agric. Food Chem. 2009, 57, 62-68.

(26) Sobolev, V.; Arias, R.; Goodman, K.; Walk, T.; Orner, V.; Faustinelli, P.; Massa, A. Suppression of aflatoxin production in Aspergillus species by selected peanut (Arachis hypogaea) stilbenoids. J. Agric. Food Chem. 2018, 66, 118-126.

(27) Sobolev, V. S.; Guo, B. Z.; Holbrook, C. C.; Lynch, R. E. Interrelationship of phytoalexin production and disease resistance in selected peanut genotypes. J. Agric. Food Chem. 2007, 55, 2195-2200.

(28) Wang, H.; Lei, Y.; Yan, L.; Cheng, K.; Dai, X.; Wan, L.; Guo, W.; Cheng, L.; Liao, B. Deep sequencing analysis of transcriptomes in Aspergillus flavus in response to resveratrol. BMC Microbiol. 2015, 15, 182.

(29) Kim, J. H.; Yu, J.; Mahoney, N.; Chan, K. L.; Molyneux, R. J.; Varga, J.; Bhatnagar, D.; Cleveland, T. E.; Nierman, W. C.; Campbell, B. C. Elucidation of the functional genomics of antioxidant-based inhibition of aflatoxin biosynthesis. Int. J. Food Microbiol. 2008, 122, 49-60.

(30) Kim, J. H.; Campbell, B. C.; Yu, J.; Mahoney, N.; Chan, K. L.; Molyneux, R. J.; Bhatnagar, D.; Cleveland, T. E. Examination of fungal stress response genes using Saccharomyces cerevisiae as a model system: targeting genes affecting aflatoxin biosynthesis by Aspergillus flavus Link. Appl. Microbiol. Biotechnol. 2005, 67, 807-815.

(31) Wang, H.; Huang, J.; Lei, Y.; Yan, L.; Wang, S.; Jiang, H.; Ren, X.; Lou, Q.; Liao, B. Relationship of resveratrol content and resistance to aflatoxin accumulation caused by Aspergillus flavus in peanut seeds. Zuowu Xuebao 2012, 38, 1875-1883.

(32) Sobolev, V. S.; Deyrup, S. T.; Gloer, J. B. New peanut (Arachis hypogaea) phytoalexin with prenylated benzenoid and but-2-enolide moieties. J. Agric. Food Chem. 2006, 54, 2111-2115.

(33) Aisyah, S.; Gruppen, H.; Slager, M.; Helmink, B.; Vincken, J.-P. Modification of prenylated stilbenoids in peanut (Arachis hypogaea) seedlings by the same fungi that elicited them: The fungus strikes back. J. Agric. Food Chem. 2015, 63, 9260-9268.

(34) Williams, E. J.; Drexler, J. S. A non-destructive method for determining peanut pod maturity. Peanut Sci. 1981, 8, 134-141.

(35) Arias, R. S.; Dang, P. M.; Sobolev, V. S. RNAi-mediated control of aflatoxins in peanut: Method to analyze mycotoxin production and transgene expression in the peanut/Aspergillus pathosystem. J. Visualized Exp. 2015, 106, No. e53398.

(36) Sobolev, V. S.; Dorner, J. W. Cleanup procedure for determination of aflatoxins in major agricultural commodities by liquid chromatography. J. AOAC Int. 2002, 85, 642-645.

(37) Wei, T.; Simko, V. corrplot: Visualization of a Correlation Matrix, version $0.84 ; 2017$. 
(38) R core team. R: A Language and Environment for Statistical Computing; R Foundation for Statistical Computing: Vienna, Austria. 2018.

(39) Chang, J.-C.; Lai, Y.-H.; Djoko, B.; Wu, P.-L.; Liu, C.-D.; Liu, Y.W.; Chiou, R. Y.-Y. Biosynthesis enhancement and antioxidant and anti-inflammatory activities of peanut (Arachis hypogaea L.) arachidin1, arachidin-3, and isopentadienylresveratrol. J. Agric. Food Chem. 2006, 54, 10281-10287. 